\title{
Entendendo o trabalho colaborativo em educação e revelando seus benefícios ${ }^{1}$
}

\section{Understanding collaborative work in education and revealling its benefits}

\author{
Magda Floriana Damiani*
}

\begin{abstract}
RESUMO
Este trabalho tem como objetivo discutir e afirmar a importância do desenvolvimento de atividades colaborativas nas escolas. O texto está baseado em ampla revisão de literatura voltada para: a teorização acerca dos processos psicológicos envolvidos nesse tipo de atividades, com base, principalmente, na psicologia sócio-histórica; e a análise dos resultados de diferentes investigações que enfocaram as atividades colaborativas entre professores e estudantes, de maneira a retirar delas algumas conclusões úteis para o trabalho em Educação. A revisão foi realizada com base em pesquisas publicadas em livros, artigos de periódicos, teses, dissertações e anais de eventos tradicionais da área, no Brasil e em outros países. Ela inclui, também, pesquisas desenvolvidas no âmbito do projeto "Trabalho colaborativo em Educação: desenvolvimento e benefícios", coordenado pela autora deste texto, que vem se dedicando, nos últimos cinco anos, a estudar a temática. O texto não tem a pretensão de constituir-se em um "estado da arte" sobre o trabalho colaborativo, sendo possível, inclusive, que não inclua resultados de investigações consideradas fundamentais por outros pesquisadores. Devido à extensão da produção relacionada ao assunto, sua revisão exaustiva seria tarefa infindável. Assim, apresenta dados de estudos considerados metodologicamente sólidos e teoricamente relevantes que foram reunidos com o objetivo de resumir e divulgar, pelo menos em parte, o conhecimento já produzido sobre a importância do trabalho colaborativo na Educação.

Palavras-chave: trabalho colaborativo, trabalho docente, aprendizagem, psicologia sócio-histórica.

${ }^{1} \mathrm{O}$ trabalho recebeu auxílio por parte do $\mathrm{CNPq}$ (financiamento, bolsa de produtividade e bolsas de iniciação científica) e da FAPERGS (bolsa de iniciação científica).

* Doutora em Educação pelo Institute of Education, University of London. Docente do Programa de Pós-Graduação em Educação, Faculdade de Educação, Universidade Federal de Pelotas (RS) E-mail: magda@ufpel.tche.br.
\end{abstract}




\begin{abstract}
The paper has the aim of discussing and asserting the importance of collaborative activities in schools. It has been based on a wide range literature reviews directed to: a) theorizing about the psychological processes involved in these activities, guided mainly by Socio-historic psychology; and b) analyzing the results of different investigations that focused on collaborative activities among teachers and students, in order to draw some useful conclusions about the area of education. The review was carried out with the help of research reports published in books, journals, theses, dissertations and annals of traditional events in Brazil and other countries. It also includes the results of investigations taken place within the research project "Collaborative work in Education: development and benefits", coordinated by the author, who has been dedicated to this study of collaborative work for the last five years. The text is not intended to constitute to be "state of the art" about the subject. It might even fail to include findings of investigations considered important by other researchers. Due to the extent of the production related to this topic, its complete revision would be never-ending. Therefore, the paper presents pieces of works considered to be methodologically sound and theoretically relevant and have been collected with the aim of summarizing and publicizing, at least in part, the knowledge produced about the importance of collaborative work in Education.
\end{abstract}

Key words: collaborative work, teacher work, learning, Socio-historic psychology.

\title{
O que se entende por trabalho colaborativo
}

Segundo Parrilla (1996, apud ARNAIZ, HERRERO, GARRIDO e DE HARO, 1999), grupos colaborativos são aqueles em que todos os componentes compartilham as decisões tomadas e são responsáveis pela qualidade do que é produzido em conjunto, conforme suas possibilidades e interesses.

Os estudos voltados para o trabalho em grupo adotam, alternadamente ou como sinônimos, os termos colaboração e cooperação para designá-lo. Costa (2005) argumenta que, embora tenham o mesmo prefixo (co), que significa ação conjunta, os termos se diferenciam porque o verbo cooperar é derivado da palavra operare - que, em latin, quer dizer operar, executar, fazer funcionar de acordo com o sistema - enquanto o verbo colaborar é derivado de laborare - trabalhar, produzir, desenvolver atividades tendo em vista determinado fim. 
Assim, para esse autor, na cooperação, há ajuda mútua na execução de tarefas, embora suas finalidades geralmente não sejam fruto de negociação conjunta do grupo, podendo existir relações desiguais e hierárquicas entre os seus membros. $\mathrm{Na}$ colaboração, por outro lado, ao trabalharem juntos, os membros de um grupo se apóiam, visando atingir objetivos comuns negociados pelo coletivo, estabelecendo relações que tendem à não-hierarquização, liderança compartilhada, confiança mútua e co-responsabilidade pela condução das ações.

Fullan e Hargreaves (2000), ao estudarem as características que as culturas de trabalho conjunto podem adquirir nas escolas, apontam que "a simples existência de colaboração não dever ser confundida com a consumação de uma cultura de colaboração" (p.71, no original). Eles descrevem formas alternativas de colaboração que, apesar de envolverem trabalho conjunto, não constituem culturas colaborativas por apresentarem subgrupos em disputa, ações conjuntas apenas ocasionais ou ações reguladas de maneira diretiva pela direção das instituições.

Torres, Alcântara e Irala (2004) salientam que, apesar de suas diferenças teóricas e práticas, ambos os termos (cooperação e colaboração) derivam de dois postulados principais: rejeição ao autoritarismo e promoção da socialização, não só pela aprendizagem, mas, principalmente, na aprendizagem. Eles argumentam que a colaboração pode ser entendida como uma filosofia de vida, enquanto que a cooperação seria vista como uma interação projetada para facilitar a realização de um objetivo ou produto final.

\section{Contribuições da Psicologia para o entendimento dos processos envolvidos no trabalho colaborativo}

Vygotsky (1989) é um dos autores que vem embasando um grande número de estudos voltados para o trabalho colaborativo na escola. Ele argumenta que as atividades realizadas em grupo, de forma conjunta, oferecem enormes vantagens, que não estão disponíveis em ambientes de aprendizagem individualizada. O autor explica que a constituição dos sujeitos, assim como seu aprendizado e seus processos de pensamento (intrapsicológicos), ocorrem mediados pela relação com outras pessoas (processos interpsicológicos). Elas produzem modelos referenciais que servem de base para nossos comportamentos e raciocínios, assim como para os significados que damos às coisas e pessoas. Nesse sentido, Álvares e Del Rio (1996) consideram que quem aprende "toma emprestado", paulatinamente, tais modelos de seus interlocutores mais capacitados, podendo 
assim chegar a ultrapassar seus limites. Segundo Vygotsky (1998), a imitação constitui-se em uma atividade essencial na aprendizagem. Ela promove o que denominou internalização - processo que se distingue da cópia porque implica em uma reconstrução interna de operações externas, na qual o sujeito desempenha um papel ativo e tem possibilidade de desenvolver algo novo. Em seu livro A formação social da mente (1998), ele pergunta: "por acaso é de se duvidar que [...], através da imitação dos adultos e através da instrução recebida de como agir, a criança desenvolve um repositório completo de habilidades?” (p. 110)

A idéia a respeito do caráter eminentemente social da consciência humana, como afirmam inúmeros pesquisadores pós-vygotskianos, pode ser também encontrada nos trabalhos de um outro russo, contemporâneo de Vygotsky: Bakhtin (1986). Freitas (1997) explica que ambos os autores concebiam a vida mental (consciência) como mediada principalmente pela linguagem (entre outros sistemas de signos, considerados como ferramentas mentais), que é o que diferencia os seres humanos dos animais. Para os dois teóricos, todo signo é um fenômeno exterior, criado em terreno interindividual, no curso de interações sociais. O signo tem função geradora e organizadora dos processos psicológicos, já que a experiência alheia somente pode ser assimilada por meio da comunicação. Para detalhar melhor essa idéia, Freitas (1997, p.320) explica que:

O outro é, portanto, imprescindível tanto para Bakhtin como para Vygotsky. Sem ele o homem não mergulha no mundo sígnico, não penetra na corrente da linguagem, não se desenvolve, não realiza aprendizagens, não ascende às funções psíquicas superiores, não forma a sua consciência, enfim não se constitui como sujeito. O outro é peça importante e indispensável de todo o processo dialógico que permeia ambas as teorias. (FREITAS, 1997, p. 320)

Bakhtin (1986) explicava que as palavras que se usam não provêm de um dicionário, mas sim de outras pessoas. Ele acreditava que as pessoas desenvolvem, inicialmente, um processo de "ventriloquismo", isto é, "falam pela boca dos outros", para depois apossar-se das palavras utilizadas e imprimir-lhes seu próprio "sotaque", adaptando-as a seus sentidos e intenções expressivas particulares.

A importância da imitação para a aprendizagem também fica clara na discussão do conceito de "Zona de Desenvolvimento Proximal" (ZDP), criado por Vygotsky (1998). O autor escreveu que aquilo que uma criança pode realizar 
hoje somente com ajuda, ou em colaboração, amanhã poderá realizar sozinha, de maneira independente e eficiente. A ZDP seria, então, a área onde estão esses conhecimentos/essas habilidades que têm potencial para ser internalizados/ desenvolvidos por meio da mediação de outros seres humanos ou de artefatos culturais. Embora Vygotsky estivesse teorizando acerca do desenvolvimento da mente infantil quando escreveu sobre a ZDP, acredita-se que tal conceito se aplique a todos os seres humanos, de qualquer idade.

Engeström (1994) argumenta que o ato de pensar está aninhado em atividades socialmente organizadas e historicamente formadas, apresentando, assim, um caráter interativo, dialógico e argumentativo. Lave e Wenger (1991), que estudam os processos de aprendizagem em situações não-formais, descrevem o que ocorre no que denominam comunidades de prática - grupos que formam uma entidade social e estão envolvidos em empreendimentos conjuntos. Os autores (2002) afirmam que é pelo engajamento em atividades cotidianas, desenvolvidas em seu grupo de trabalho, que ocorre a produção, transformação e mudança na identidade das pessoas, em seu conhecimento e em suas habilidades práticas. Desenvolvendo mais essa idéia, Schaffer (2004) explica que, pela participação em comunidades de prática, os indivíduos internalizam as normas, os hábitos, as expectativas, as habilidades e os entendimentos dessas comunidades (como, por exemplo, as comunidades profissionais), que apresentam maneiras singulares de conhecer, decidir o que é importante saber e entender a realidade.

$\mathrm{Na}$ revisão que realizaram sobre os mecanismos que atuam para potencializar as aprendizagens em ambientes de colaboração, Jeong e Chi (1997) relatam que pesquisas realizadas nas áreas da Antropologia, Lingüística e Ciência Organizacional sugerem que as pessoas passam a compartilhar memórias, conhecimentos, ou modelos mentais como resultado do trabalho em conjunto. Dessa forma, atingem significados e representações comuns, possivelmente mais complexos e ricos do que aqueles elaborados individualmente. A respeito desse aspecto, também Salomon e Perkins (1998) salientam a possibilidade de "objetivação" (p.4) dos pensamentos, das idéias ainda em formação, que ocorre no trabalho colaborativo. Tais pensamentos e idéias, quando comunicados e compartilhados, podem ser discutidos, examinados e aperfeiçoados como se fossem objetos externos.

Wells (2001), outro pesquisador que segue as idéias de Vygotsky, descreve o que ocorre entre pessoas que tentam resolver um problema significativo para todos e estabelecem um diálogo no qual soluções são propostas, ampliadas, modificadas ou contrapostas. A isso ele chama de co-construção do conhecimento, considerando-a como parte essencial do processo de aprendizagem. 


\section{A importância do trabalho colaborativo entre professores}

As tentativas de minimizar os índices de reprovação e manter todos os jovens nas escolas, juntamente com as políticas relacionadas à inclusão de alunos com necessidades especiais nas redes regulares, têm criado uma série de dificuldades às instituições e aos docentes. Esse tipo de situação pode criar, nos professores, estados de ansiedade e esgotamento profissional (CODO, 1999; ARAÚJO, 2003).

Ao tratar dos problemas engendrados pelas dificuldades do trabalho escolar, Parrilla e Daniels (2004, p.10-11) comentam que elas levam os docentes a se sentirem carentes de apoio, o que pode resultar na falta de iniciativa para encontrar soluções novas para os problemas, com a conseqüente adoção de práticas corriqueiras, sem esperanças de que funcionem. Essa descrição, embora se refira ao sistema de educação espanhol, parece adequada também à realidade das escolas brasileiras.

Norwich e Daniels (1997) propõem que se analise a forma de enfrentar as dificuldades do trabalho docente a partir de dois parâmetros principais complementares e inter-relacionados: engajamento ativo, que se refere à maneira pela qual os professores tentam proporcionar, a todos, oportunidades de aprendizagem de boa qualidade; e nível de tolerância, que diz respeito aos limites dos desafios que os professores conseguem enfrentar. Daniels (2000) argumenta que as culturas de trabalho colaborativo são importantes ambientes para a promoção de trocas de experiência e, conseqüentemente, de aprendizagens, promovendo incremento nesses parâmetros. Segundo Araújo (2004), quando o que denomina "cultura de coletividade" é instaurada, as pessoas nela envolvidas passam a reconhecer o que sabem, o que os outros sabem e o que todos não sabem - atitudes que resultam na busca de superação dos limites do grupo. Nono e Mizukami (2001) salientam a importância do compartilhamento de experiências entre professores, explicando que pode favorecer o desenvolvimento da destreza na análise crítica, na resolução de problemas e na tomada de decisões.

A partir do que foi exposto, pode-se pensar que o trabalho colaborativo entre professores apresenta potencial para enriquecer sua maneira de pensar, agir e resolver problemas, criando possibilidades de sucesso à difícil tarefa pedagógica. Esse tipo de trabalho vem sendo considerado importante a ponto de Hargreaves, citado por Engeström (1994, p.45), afirmar que ele pode "modificar radicalmente a natureza do pensamento do professor". Entretanto, ao longo da 
história, os professores vêm trabalhando individualmente e essa tendência parece não ter mudado.

Engeström (1994) - da Finlândia - Hargreaves (1998) e Fullan e Hargreaves (2000) - do Canadá - e Thurler (2001) - da Suíça descrevem a profissão docente como solitária. Fullan e Hargreaves (2000) sugerem que o isolamento docente tem raízes em fatores como a arquitetura das escolas, a estrutura dos seus horários, a sobrecarga de trabalho e a própria história da profissão docente. Essa idéia é também corroborada por Engeström (1994) e por Pimenta (2005) - esta se referindo ao nosso país.

Os professores das escolas brasileiras, como comenta Martins (2002), estão, na maior parte do tempo, dispersos. Há momentos de organização, como nos encontros nas salas de professores, nos conselhos de classe, nos grupos que trabalham com as mesmas disciplinas ou nos horários de trabalho pedagógico coletivo. Esses momentos, entretanto, acabam sendo utilizados muito mais para a realização de atividades burocráticas e resolução de problemas emergenciais do que para criar "um espaço para reflexão, planejamento e transformação de sua prática educacional em atividades humanizadoras para si mesmo e para seus alunos" (p.233).

Em meio a essas argumentações acerca das potencialidades positivas do trabalho colaborativo, no entanto, vale considerar as idéias de Góes (1997, p.27), que adverte:

o jogo dialógico entre sujeitos não tende a uma só direção; ao contrário, envolve circunscrição, ampliação, dispersão e estabilização de sentidos. Um determinado conhecimento (pretendido, na intencionalidade do outro; ou previsto, na perspectiva de um observador) pode ou não ser construído pelo indivíduo.(GÓES, 1997, p. 27)

Pensando nisso, é importante observar que, ao valorizar o trabalho colaborativo, não se nega a importância da atividade individual na docência. Como Fullan e Hargreaves (2000, p. xi), defende-se a reconciliação dos dois tipos de atividades - grupais e individuais - entendendo que qualquer delas, sem a outra, limita o potencial de trabalho dos professores. 


\section{O que dizem as pesquisas sobre os efeitos do trabalho colaborativo entre professores}

Creese, Norwich e Daniels (1998), baseados em amplo estudo realizado na Inglaterra, apresentam evidências de que escolas em que predominam culturas colaborativas são mais inclusivas, isto é, apresentam menores taxas de evasão e formas mais efetivas de resolução de problemas dos estudantes. Ilustrando também os benefícios de uma cultura escolar colaborativa, a investigação de Damiani $(2004$; 2006) aponta para o bom desempenho de uma escola pública municipal, que investe nesse tipo de cultura há alguns anos. Essa escola apresenta baixos índices de repetência e evasão entre seus estudantes (quando comparada com as médias das escolas da cidade) e alto grau de satisfação e investimento em formação continuada de seus docentes. Os trabalhos de Zanata (2004) e Loiola (2005) são outros exemplos de investigações cujos achados indicam que o trabalho colaborativo entre docentes constitui-se em excelente espaço de aprendizagem, permitindo a identificação de suas forças, fraquezas, dúvidas e necessidades de reconstrução, a socialização de conhecimentos, a formação de identidade grupal e a transformação de suas práticas pedagógicas. Em relação à formação continuada, Lacerda (2002) ressalta a diferença entre a organizada pelos próprios professores, em conjunto, e a disponibilizada por meio de cursos organizados por órgãos administrativos que, usualmente, não consideram os professores como produtores de conhecimento e são estruturados apenas como fontes de transmissão de informações. A pesquisadora, que escreve sobre os ganhos resultantes de um grupo de estudos organizado por professoras alfabetizadoras, acredita que todos os profissionais da educação, não obstante suas concepções, trajetórias pessoais e conhecimentos, podem se organizar e gerir seu próprio processo de formação continuada. Essa idéia é confirmada pelo trabalho de Rausch e Schlindwein, que também investigaram os efeitos das discussões grupais por professoras que visavam refletir sobre suas práticas. As autoras explicam que: 
Para que os professores ressignifiquem a sua prática é preciso que a teorizem. E este movimento de teorizar a prática não se efetiva somente com treinamentos, palestras, seminários, aulas expositivas, mas muito mais, quando há uma relação dinâmica com a prática deste professor a partir de uma reflexão coletiva, auto-reflexão, pensamento crítico e criativo, via educação continuada. É preciso desencadear estratégias de formação processuais, coletivas, dinâmicas e contínuas. Refletir com os demais professores e compartilhar erros e acertos, negociar significados e confrontar pontos de vista surge como algo estimulador para uma prática pedagógica comprometida. (RAUSCH e SCHLINDWEIN, 2001, p. 121).

A esses resultados, podem-se acrescentar os obtidos por Santos (2006), que avalia os efeitos do trabalho de uma coordenadora pedagógica que realiza sua prática de maneira participativa, incentivando o trabalho colaborativo com e entre os professores de uma escola particular de idioma estrangeiro. Os dados dessa pesquisa revelam que os professores da instituição valorizam o trabalho conjunto, que, segundo informam, leva-os a se sentirem respeitados e valorizados, assim como a desenvolver sua autonomia.

Com o objetivo de iniciar professores em relação à utilização de novas tecnologias de informação e comunicação (TICs) na Educação Especial, a pesquisa de Beck (2004) também presta testemunho à importância do trabalho desenvolvido por meio de discussões e atividades grupais. A autora argumenta que não basta ter computadores ligados à internet, por exemplo, para garantir que eles serão efetivamente utilizados e incorporados na prática escolar. É necessário um trabalho de reflexão coletiva para que essa mídia traga novos elementos à, já bastante atribulada, vida do professor.

Os benefícios dos grupos de discussão e do trabalho colaborativo entre professores brasileiros, para a melhoria de sua autoconfiança e maior efetividade de seu trabalho, também são evidenciados em trabalhos como os de Passos (1999), Magalhães e Celani (2000), Dickel, Colussi, Bragagnolo e Andreolla (2002), Detsch e Gonçalves (2002) e Silva (2002). 


\section{O trabalho colaborativo entre os estudantes}

Os benefícios das atividades colaborativas entre estudantes têm sido ressaltados, da mesma forma que entre docentes, por diversos autores. Os trabalhos de Coll Salvador (1994) e Colaço (2004) são exemplos dos que realizam uma análise ampla dos efeitos desse tipo de atividade entre estudantes. Esses autores apontam ganhos em termos de: 1) socialização (o que inclui aprendizagem de modalidades comunicacionais e de convivência), controle dos impulsos agressivos, adaptação às normas estabelecidas (incluindo a aprendizagem relativa ao desempenho de papéis sociais) e superação do egocentrismo (por meio da relativização progressiva do ponto de vista próprio); 2) aquisição de aptidões e habilidades (incluindo melhoras no rendimento escolar); e 3) aumento do nível de aspiração escolar.

Nos Estados Unidos da América, o North Central Region Education Laboratory vem desenvolvendo estudos sobre a sala de aula colaborativa. O trabalho de Tinzman, Jones, Fennimore et al. (1990), que participam de tal instituição, salienta as vantagens das atividades compartilhadas, afirmando que tanto a comunicação quanto a colaboração são aspectos essenciais para que uma pessoa se torne um aprendiz bem-sucedido. Segundo Forman e McPhail (1993), a escola não oportuniza às crianças ocasiões nas quais possam exercitar suas habilidades comunicativas: os estudantes, usualmente, na sala de aula, ficam restritos a responder as perguntas feitas pelos professores. As autoras observam que trabalho colaborativo entre estudantes, quando envolvem a solução de problemas, possibilita-lhes fazer uso efetivo desses registros, pois necessitam se engajar em argumentações lógicas, expor idéias para trabalhar conjuntamente.

Colaço (2004) observa que as crianças, ao trabalharem juntas, "orientam, apoiam, dão respostas e inclusive avaliam e corrigem a atividade do colega, com o qual dividem a parceria do trabalho, assumindo posturas e gêneros discursivos semelhantes aos do professor" (2004, p.339). Isso leva a perceber a importância de o professor tanto estimular seus estudantes a trabalhar em grupo quanto fornecer-lhes um modelo interativo que leve ao compartilhamento de idéias e não à intervenção autoritária e diretiva, que ocorre quando um estudante apenas corrige o trabalho do colega, como observa Moysés (1997). Assim, parece que o professor desempenha papel importante na promoção de benefícios do trabalho em grupo entre seus estudantes, tanto servindo como modelo de interação quanto organizando grupos de estudantes que possam tornar o trabalho frutífero (MARTINS, 2002). A preocupação com a composição dos grupos justifica-se porque nem sempre uma interação entre pares com diferentes graus de adian- 
tamento provocará o desenvolvimento do membro menos avançado, como adverte Tudge (1996). Pode haver, também, uma regressão do mais adiantado, se este não tiver suficiente autoconfiança para valorizar e fazer predominar seus conhecimentos.

\section{O que dizem as pesquisas sobre os efeitos do trabalho colaborativo entre estudantes}

A investigação de Jeong e Chi (1997) sugere que pares de estudantes universitários, após estudo conjunto sobre conceitos de Biologia, passaram a compartilhar modelos mentais e conhecimentos, avançando em sua compreensão do assunto tratado em aula. $\mathrm{O}$ favorecimento de aprendizagens em uma disciplina do Curso de Pedagogia, assim como no desenvolvimento do estágio curricular, realizado em duplas, também foi verificado por Damiani (2006). Essa investigação aponta o valor das constantes interações entre pares para a criação de questionamentos sobre as estruturas de conhecimentos já adquiridos, assim como para a exposição a diferentes raciocínios e comportamentos que podem ser apropriados por meio da imitação criativa e não-reprodutiva, enriquecendo o repertório de pensamento e a ação dos estudantes. Da mesma forma, Barros, Remold, da Silva e Tagliati (2004) reportam ganhos significativos, em termos de compreensão conceitual e entusiasmo em relação à aprendizagem, obtidos por meio de discussões grupais de alunos de um curso de graduação em Física. Segundo os autores, um número significativo de alunos expressou o desejo de que essas atividades fossem estendidas para outras disciplinas e passou a utilizá-las também fora do contexto de aula, o que raramente ocorria em semestres anteriores. Resultados semelhantes encontram-se na dissertação de Garcia (2006), que avaliou o trabalho desenvolvido por pares de estudantes de curso técnico em eletrônica, ao desenvolver projeto conjunto de construção de equipamentos. A pesquisa evidenciou aumento de motivação e de aprendizagens significativas que se ampliaram para além dos conteúdos escolares. Professores e estudantes enfatizaram a importância das atividades colaborativas desenvolvidas tanto para essas aprendizagens como para o desenvolvimento de autonomia na a resolução de problemas.

Em relação às atividades de aprendizagem colaborativa entre crianças, encontramos, nos trabalhos de Leal e Luz (2001) e Pessoa (2002), evidências relevantes acerca dos benefícios por elas proporcionados. O primeiro trabalho está voltado para a atividade de composição de textos por pares de estudantes 
do ensino fundamental, constatando que esse tipo de trabalho favorece a tomada de consciência de decisões sobre a escrita, desautomatizando-a e melhorando sua qualidade. O segundo trabalho, ao analisar o papel da atividade em duplas para a superação de dificuldades relativas à resolução de problemas em aulas de Matemática, sugere um decréscimo no percentual de erros entre o pré e o pós-teste, tendo as crianças passado a criar diferentes estratégias para superar as dificuldades, a partir das discussões com os companheiros (estratégias essas que, mais tarde, passaram a ser utilizadas nos trabalhos individuais). A pesquisa de Carvalho (2006), por seu turno, mostra a possibilidade da construção de aulas de Educação Física colaborativas, indo de encontro ao clima competitivo geralmente existente nessa disciplina. A pesquisadora/professora desenvolveu, com os alunos, atividades desportivas modificadas, em que a inclusão de todos era o objetivo principal. Para isso, as regras dos desportos foram adaptadas, criando uma cultura de solidariedade e participação entre os estudantes de $5^{\mathrm{a}}$ série do ensino fundamental. Os dados mostram que os alunos passaram a perceber a importância dos jogos colaborativos para a inclusão de todos os colegas, tendo uma atitude crítica em relação a atividades competitivas desenvolvidas em outras disciplinas.

Benefícios das interações entre estudantes, em seus processos de aprendizagem, são igualmente ilustrados nos trabalho de Candela (2000) e López de Lara (2000), do México, e de Ambrosetti (1999), do Brasil.

\section{Comentários conclusivos}

Neste estudo, pretendeu-se argumentar a favor do desenvolvimento de atividades colaborativas entre professores e entre estudantes sem, no entanto, propor - da mesma forma que Martins, em seu texto sobre a temática - "a mistificação das atividades grupais na sala de aula e nos espaços escolares" (2002, p. 234), considerando-as como a panacéia para os problemas da Educação. Visou-se agregar e dar visibilidade a um conjunto de evidências, que se vêm acumulando na literatura, sobre a importante contribuição do trabalho colaborativo para essa área de atividade humana. A revisão das investigações acerca do trabalho colaborativo - em suas diferentes formas - assim como o entendimento do processo que o sustenta sugerem que esse tipo de atividade apresenta potencial para auxiliar no enfrentamento dos sérios desafios propostos pela escola atual em nosso país. A literatura indica que o desenvolvimento de atividades de maneira colegiada pode criar um ambiente rico em aprendizagens acadêmicas e sociais tanto para 
estudantes como para professores, assim como proporcionar a estes um maior de grau de satisfação profissional. $\mathrm{O}$ trabalho colaborativo possibilita, além disso, o resgate de valores como o compartilhamento e a solidariedade - que se foram perdendo ao longo do caminho trilhado por nossa sociedade, extremamente competitiva e individualista. Como argumenta Naura Ferreira (2003, p.134), "juntamos trabalhos" ao invés de trabalharmos juntos, e isso se aplica, de maneira intensa, às instituições escolares, nas quais tanto as atividades pedagógicas quanto as administrativas são, usualmente, realizadas de maneira individual.

Embora o espaço aqui disponível não permitisse que toda a riqueza de possibilidades oferecidas pelo trabalho colaborativo fosse revelada, acredita-se que as evidências apresentadas são suficientes para afirmar que esse tipo de trabalho é importante e deve, portanto, ser entendido e discutido tanto nos cursos de formação inicial quanto nos programas de formação continuada de docentes.

\section{REFERÊNCIAS}

AMBROSETTI, N. B. O "eu" e o "nós": trabalhando com a diversidade em sala de aula. In: ANDRÉ, M. (Org.). Pedagogia da diferenças na sala de aula. Campinas: Papirus, 1999.

ALVAREZ, A.; DEL RIO, P. Educação e desenvolvimento: a teoria de Vygotsky e a zona de desenvolvimento próximo. In: COLL SALVADOR, C.; PALACIOS, J.; MARCHESI, A. (Org.). Desenvolvimento psicológico e educação. Porto Alegre: Artes Médicas, 1996. v. 2.

ARAÚJO, T. M. de et al. Trabalho docente e sofrimento psíquico: um estudo entre professores de escolas particulares de Salvador, Bahia. Educação e Contemporaneidade, Salvador, v. 12, n. 20, p. 485-495, jul./dez. 2003.

ARAÚJO, E. S. A aprendizagem e o desenvolvimento profissional docente sob as luzes da perspectiva histórico-cultural. In: ENCONTRO NACIONAL DE DIDÁTICA E PRÁTICA DE ENSINO, 12., Curitiba, 2004. Anais... Curitiba, 2004. p. 3507-3518. CD-ROM.

ARNAIZ, P. et al. Trabajo colaborativo entre profesores y atención a la diversidad. Comunidad Educativa, n. 262, p. 29-35, 1999.

BAKHTIN, M. M. Speech Genres and Other Late Essays. Austin: University of Texas Press, 1986. 
BARROS, J. A. et al. Revista Brasileira de Ensino de Física, São Paulo, v. 26, n. 1, p. 63-69, 2004.

BECK, F. L. A utilização da tecnologia computacional na educação especial: uma proposta de intervenção na prática docente. Dissertação (Mestrado em Educação) Faculdade de Educação, Universidade Federal de Pelotas, Pelotas, 2004.

CANDELA, A. Co-construcción de conocimiento en contextos escolares. In: CONFERÊNCIA DE PESQUISA SÓCIO-CULTURAL, 3., Campinas, 2000. Anais... Campinas, 2000. p. 1-38. CD-ROM.

CARVALHO, M. C. Trabalho colaborativo na aula de educação física: sistemas de atividade em ação. Dissertação (Mestrado em Educação) - Faculdade de Educação, Universidade Federal de Pelotas, Pelotas, 2006.

COLAÇO, V. de F. R. Processos interacionais e a construção de conhecimento e subjetividade de crianças. Psicologia: Reflexão e Crítica, Porto Alegre, v. 17, n. 3, p. 333-340, 2004.

CODO, W. (Org.). Educação: carinho e trabalho. Petrópolis: Vozes, 1999.

COLL SALVADOR, C. Aprendizagem escolar e construção do conhecimento. Porto Alegre: Artes Médicas, 1994.

CREESE, A; DANIELS, H.; NORWICH, B. Teacher Support Teams in Primary and Secondary Schools. London: Fulton, 1997.

DAMIANI, M. F. “Sem as reuniões a escola não existe! Não tem como!”: estudo de caso de uma escola colaborativa. In: REUNIÃO ANUAL DAANPED, 27., Caxambu, 2004. Anais... Caxambu, 2004. p. 1-15. CD-ROM.

. A teoria da atividade como ferramenta para entender o desempenho de duas escolas de ensino fundamental. In: REUNIÃO ANUAL DA ANPED, 29., Caxambu, 2006. Anais... Caxambu, 2006. p. 1-15. CD-ROM.

DETSCH, R. J.; GONÇALVES, M. A. S. Criação cooperativa de um laboratório na escola: uma experiência de construção de normas de interação social. In: SEMINÁRIO DE PESQUISA EM EDUCAÇÃO DA REGIÃO SUL (ANPED-SUL), 4., Florianópolis, 2002. Anais... Florianópolis, 2002. p. 1-8. CD-ROM.

DICKEL, A. et al. Em um processo de formação continuada, a possibilidade de articulação entre teoria e prática: reflexões sobre uma experiência compartilhada. In: SEMINÁRIO DE PESQUISA EM EDUCAÇÃO DA REGIÃO SUL (ANPED-SUL), 4., Florianópolis, 2002. Anais... Florianópolis, 2002. p. 1-10. CD-ROM. 
ENGESTRÖM, Y. Teachers as collaborative thinkers: activity-theoretical study of an innovative teacher team. In: CARLGREN, I; HANDAL, G.; VAAGE, S. Teachers minds and actions: research on teachers' thinking and practice. London: Falmer Press, 1994.

FORMAN, E.; McPHAIL, J. Vygotskian perspective on children's collaborative problem-solving activities. In: FORMAN, E.; MINICK, N.; ADDISON-STONE, C. (Ed.). Contexts for Learning: sociocultural dynamics in children's development. New York: Oxford University Press, 1993.

FERREIRA, A. C. Metacognição e desenvolvimento profissional de professores de Matemática: uma experiência de trabalho colaborativo. Tese (Doutorado em Educação) - Universidade Estadual de Campinas, Campinas, 2003.

FERREIRA, N. S. C. Poderemos trabalhar juntos na sociedade mundializada? Desafios para os educadores. In: PORTO, T. M. E. Redes em construção: meios de comunicação e práticas educativas. Araraquara: JM, 2003.

FREITAS, M. T. de A. Nos textos de Bakhtin e Vygotsky: um encontro possível. In: BRAIT, B. Bakhtin, dialogismo e construção de sentido. Campinas: Editora Unicamp, 1997.

FULLAN, M.; HARGREAVES, A. A escola como organização aprendente: buscando uma educação de qualidade. 2. ed. Porto Alegre: Artes Médicas, 2000.

GARCIA, D. E. S. Metodologia de projetos: vivências, resolução de problemas e colaboração na experiência educativa. Dissertação (Mestrado em Educação) Faculdade de Educação, Universidade Federal de Pelotas, Pelotas, 2006.

GOÉS, M. C. R. As relações intersubjetivas na construção de conhecimentos. In: GOÉS, M. C. R.; SMOLKA, A. L. B. (Org.). A significação nos espaços educacionais: interação social e subjetivação. Campinas: Papirus, 1997.

JEONG, H.; CHI, M. T. H. Construction of shared knowledge during collaborative learning. In: R. HALL, R.; MIYAKE, N.; ENYEDY, J. (Ed.). International Conference On Computer Support For Collaborative Learning, 2., Toronto, 1997. Annals... Toronto, 1997. p. 1-5.

LACERDA, M. P. Quando falam as professoras alfabetizadoras. Rio de Janeiro: DP\&A, 2002.

LAVE, J., WENGER, E. Situated learning: legitimate peripheral participation. Cambridge: Cambridge University Press, 1991. 
. Prática, pessoa, mundo social. In: DANIELS, H. (Org.). Uma introdução a Vygotsky. São Paulo: Loyola, 2002.

LEAL, T. F.; LUZ P. S. da L. A produção de textos narrativos em pares: reflexões sobre o processo interativo. Educação e Pesquisa, São Paulo, v. 27, n. 1, p. 27-45, jan./jun. 2001.

LOIOLA, L. J. S. L. Contribuições da pesquisa colaborativa e do saber prático contextualizado para uma proposta de formação continuada de professores de educação infantil. In: REUNIÃO ANUAL DA ANPED, 28., Caxambu, 2005. Anais... Caxambu, 2005. p. 1-16. CD-ROM.

LÓPEZ DE LARA, Y. de la G. Colaboración entre iguales e aprendizage escolar. In: CONFERÊNCIA DE PESQUISA SÓCIO-CULTURAL, 3., Campinas, 2000. Anais... Campinas, 2000. p. 1-18. CD-ROM.

MAGAlhãES, M. C. C.; CELANI, M. A. Continuing education: teachers' collaboration in the construction of meaning in their classroom discourse practices. In: III CONFERÊNCIA DE PESQUISA SÓCIO-CULTURAL, 3., Campinas, 2000. Anais... Campinas, 2000. p. 1-29. CD-ROM.

MARTINS, S. T. F. Educação científica e atividade grupal na perspectiva sócio-histórica. Ciência \& Educação, Bauru, v. 8, n. 2, p. 227-235, 2002.

MOYSÉS, L. Aplicações de Vygotsky à educação matemática. Campinas: Papirus, 1997.

NONO, M. A.; MIZUKAMI, M. da G. N. Aprendendo a ensinar: futuras professoras das séries iniciais do ensino fundamental e casos de ensino. In: REUNIÃO ANUAL DA ANPED, 24., Caxambu, 2001. Anais... Caxambu, 2001. p. 1-16. CD-ROM.

NORWICH, B.; DANIELS, H. Teacher support Teams for special educational needs in primary schools: evaluating a teacher-focused support scheme. Educational Studies, v. 23, n. 1, p. 5-24, 1997.

PARRILLA, A.; DANIELS, H. Criação e desenvolvimento de grupos de apoio para professores. São Paulo: Loyola, 2004.

PASSOS, L. F. O projeto pedagógico e as práticas diferenciadas: o sentido da troca e da colaboração. In: ANDRÉ, M. (Org.). Pedagogia das diferenças na sala de aula. São Paulo: Papirus, 1999.

PESSOA, C. A. dos S. Interação social: uma análise do seu papel na superação de dificuldades de resolução de problemas aditivos. In: REUNIÃO ANUAL DAANPED, 25., Caxambu, 2002. Anais... Caxambu, 2002. p. 1-15. CD-ROM. 
PIMENTA, S. G. Pesquisa-ação crítico-colaborativa: construindo seu significado a partir de experiências com a formação docente. Educação e Pesquisa, São Paulo, v. 31, n. 3, p. 521-539, set./dez. 2005.

RAUSC, R. B.; SCHLINDWEIN, L. M. As ressignificações do pensar/fazer de um grupo de professoras das séries iniciais. Contrapontos, Itajaí, v. 1, n. 2, p. 109-23, 2001.

SHAFFER, D. W. Pedagogical praxis: the professions as models for post-industrial education. Teachers College Record, v. 106, n. 7, p. 1401-1421, 2004. Disponível em: $<$ http://coweb.wcer.wisc.edu/cv/papers/TCRpedprax.pdf $>$. Acesso em: 22/8/2006.

SALOMON, G.; PERKINS, D. N. Individual and social aspects of learning. Review of Research in Education, v. 23, 1998. Disponível em: < http://construct.haifa. ac.il/ gsalomon/indsoc.htm>. Acesso em: 24/2/2005.

SANTOS, A. M. Momentos pedagógicos: aprendendo (n)a prática docente. Dissertação (Mestrado em Educação) - Faculdade de Educação, Universidade Federal de Pelotas, Pelotas, 2006.

SILVA, M. da. Desenvolvendo as relações interpessoais no trabalho coletivo de professores. In: ALMEIDA, L. R. de; PLACCO V. M. de. As relações interpessoais na formação de professores. São Paulo: Loyola, 2002.

TORRES, P. L.; ALCÂNTARA, P. R.; IRALA, E. A. F. Grupos de consenso: uma proposta de aprendizagem colaborativa para o processo de ensino-aprendizagem. Revista Diálogo Educacional, Curitiba, v. 4, n.13, p. 129-145, 2004.

TUDGE, J. Vygotsky, a zona de desenvolvimento proximal e a colaboração entre pares: implicações para a prática em sala de aula. In: MOLL, L. C. Vygotsky e a educação: implicações pedagógicas da psicologia sócio-histórica. Porto Alegre: Artes Médicas, 1996.

THURLER, M. G. Inovar no interior da escola. Porto Alegre: Artmed, 2001.

TINZMAN, M. B. et al. What is the collaborative classroom? Disponível em: <http:/ www.NCREL>. Acesso em: 25/8/2001.

VYGOTSKY, L. S. Obras Escogidas II (Pensamento Y Lenguage). Moscú: Editorial Pedagógica, 1982. . A formação social da mente. 6. ed. São Paulo: Martins Fontes, 1998.

WELLS, G. Indagación dialógica: hacia una teoria y una práctica socioculturales de la educación. Barcelona: Paidós, 2001. 
ZANATA, E. M. Práticas pedagógicasi inclusivas para alunos surdos numa perspectiva colaborativa. Tese (Doutorado em Educação Especial) - Universidade Federal de São Carlos, São Carlos, 2004.

Texto recebido em 18 set. 2006 Texto aprovado em 14 abr. 2007 